\title{
Actividad física extraescolar y rendimiento académico
}

\author{
Daniel Jardón* y Encarnación Sueiro* ** \\ * Facultad de Ciencias de la Educación (U. Vigo-Campus Ourense) \\ **C.O.F. “Nóvoa Santos” (SERGAS-OURENSE)
}

\begin{abstract}
Resumen
Pretendemos conocer a practica de Actividade Física Extraescolar e si esta mellora o Rendemento Académico, mediante unha investigación descriptiva, transversal, cuantitativa, utilizando un Cuestionario aplicado en nenos/as de entre 10 e 13 anos de dous colexios de Educación Primaria e as Notas Académicas da primeira avaliación, sendo analizados co SPSS/21. Os Resultados sinalan que o $72,3 \%$ do alumnado practica Actividades Físicas Extraescolares, que a Media das Notas Académicas é de 6,77 e que o IMC se sitúa en torno a dos $20 \mathrm{~kg} / \mathrm{m}^{2}$. As diferenzas significativas $(\mathrm{p}<.05)$ indican que a práctica de Actividade Física Extraescolar ten unha influenza positiva no Rendemento Académico.

Palabras clave: Actividade física, rendemento académico, primaria, IMC,
\end{abstract}

\section{Abstract}

We want to know the Extracurricular Physical Activity and demonstrate that this practice improves Academic Performance. That was a descriptive, cross-sectional, quantitative research using a questionnaire (applied to children / as between 10 and 13 years in two primary schools) and Academic Notes first assessment being analyzed with SPSS/21. Results indicate that $72.3 \%$ of the students practiced Extracurricular Physical Activities, the Academic Average is 6.77 Notes or e BMI is around dos $20 \mathrm{~kg} / \mathrm{m}^{2}$. Significant differences $(\mathrm{p}<.05)$ seem to suggest that the practice of Extracurricular Physical Activity has a positive influence on the Academic Performance.

Keywords: Physical Activity, Academic Performance, Elementary Education, BMI,

\section{Obxectivos}

Coa presente investigación preténdese coñecer as características e preferencias do alumnado no referente ás actividades extra escolares e ó deporte, averigüar as relacións de dependencia das notas académicas con respecto ás actividades extraescolares e precisar a influeza do IMC no desenvolvemento de actividades físicas.
}

\section{Método}

\section{Participantes}

A investigación levouse a cabo con 92 nenos e nenas residentes na provincia de Ourense, de $4^{\circ}, 5^{\circ}$ e $6^{\circ}$ de Primaria, do Centro Público de Infantil e Primaria CEIP Princesa España (Verín) (o 72,82\%) e do O CEIP Mariñamansa (Ourense) (27,17\%), tendo ambos horario continuo (98,3\%), e onde o $23,91 \%$ tiñan 10 anos, o $40.22 \%$ tiñan 11 , o 31,52\% tiñan 12 e un 4,35\% tiña 13 anos. A idade media do grupo é de 11,16 anos e a D.T. $=0,84$. As mulleres son o $58,70 \%$.

Na táboa que segue, están as medias e desviacións típicas do peso, a altura e mailo IMC.

Táboa 1.

Peso, altura e IMC

\begin{tabular}{|c|c|c|c|}
\hline & Peso & Altura & IMC \\
\hline Media & 43,94 & 140,2 & 19,891 \\
\hline Dsv. típ. & 5,277 & 5,426 & 2,8459 \\
\hline
\end{tabular}

Na táboa 2 podemos comprobar cómo son os estudos das suas nais e pais.

Táboa 2.

Estudos dos proxenitores

\begin{tabular}{lcccc} 
& nais & \multicolumn{3}{c}{ pais } \\
& Frec. & $\%$ & Frec. & $\%$ \\
Ningún & 10 & 10,9 & 8 & 8,7 \\
EP & 30 & 32,6 & 23 & 25,0 \\
G. Escolar & 34 & 37,0 & 33 & 35,9 \\
Bacharelato & 10 & 10,9 & 21 & 22,8 \\
FP & 5 & 5,4 & 6 & 6,5 \\
Universidad & 3 & 3,3 & 1 & 1,1 \\
Total & 92 & 100 & 92 & 100 \\
\hline
\end{tabular}

A táboa 3 mostra ó traballo dos proxenitores. 
Táboa 3.

Traballo dos proxenitores.

\begin{tabular}{lccccc}
\hline & nais & \multicolumn{3}{c}{ pais } \\
& Frec. & $\%$ & Frec & $\%$ \\
Ama/o de casa & 33 & 35,9 & 3 & 3,3 \\
O. cualificado ou non & 24 & 26,1 & 22 & 23,9 \\
T. medio ou superior & 18 & 19,6 & 29 & 31,5 \\
Ind. ou empresario/a & 5 & 5,4 & 6 & 6,5 \\
Xub. ou pensionista & 1 & 1,1 & 4 & 4,3 \\
Paro & 11 & 12,0 & 28 & 30,4 \\
Total & 92 & 100 & 92 & 100 \\
\hline
\end{tabular}

\section{Instrumentos}

Un Cuestionario (51 preguntas, 30 comúns, 16 para quenes participaban en Actividades Físicas Extraescolares e 5 para os que non) e as Notas das materias de Coñecemento do Medio, Matemáticas, Galego, Lingua Española, Inglés, Educación Física e Educación Artística, da $1^{\mathrm{a}}$ avaliación.

\section{Procedemento}

Primeiramente, as familias tiveron que firmar un Consentimento Informado. Logo, procedeuse a aplicar o Cuestionario en cada clase tratando de solucionar as dúbidas que xurdiran. O proceso duraba en torno a 20 minutos de media para cada alumno. Finalmente, foi a recollida das Notas.

As Variables independentes analizadas foron Idade, Sexo, Peso, Altura, Notas Académicas e IMC. E as Variables dependentes: Práctica de Actividade Física e Deporte Extraescolar, Tipo de Actividad Física, Lugar de realización da Actividade Física ou Deporte Extraescolar, Tempo dedicado á Actividade Física ou Deporte Extraescolar, O Acto de Competición, Tipo de Competición e Tempo dedicado a la Competición.

Trátase dunha investigación cuantitativa, transversal, na que realizase unha estadística descriptiva (frecuencias e porcentaxes) e analítica (relación entre variables). Para o análise de datos,empregamos o SPSS/21.

\section{Resultados}

A Media da Notas académicas é de 6,77, e a D.T. $=0.8383$

O 47,8\% do alumnado afirma que estuda porque lle gusta, un $30,4 \%$ por obriga e o $10,9 \%$ porque o fan os da sua idade e por ser alguén na vida. = $69,6 \%$ fan os deberes a diario, para non ter problemas no colexio (43,75\%, porque obriga a familia $(34,38 \%)$ porque é o millor para él (17,19\% e porque depende do día (4,69\%). O 66,3 \% ten problemas para facer os deberes, recibindo axuda para facelos o $43,5 \%$, por parte de compañeiros (16,3\%), dun prpfesor particular
$(15,2 \%)$, da familia $(9,8 \%)$ e dunha academia (2,2\%). O $72,8 \%$ non realizan tarefas escolares se non teñen deberes e 0 79, $\%$ tampouco en época de vacacións. Táboa 4.

Opinión familiar e propia como estudante

\begin{tabular}{lcccc} 
& \multicolumn{3}{c}{ familia } & \multicolumn{3}{c}{ propia } \\
& Fre. & $\%$ & Frec. & $\%$ \\
Moi bo & 7 & 7,6 & 2 & 2,2 \\
Bo & 35 & 38,0 & 46 & 50,0 \\
Regular & 37 & 40,2 & 35 & 38 \\
Mal & 9 & 10,1 & 8 & 8,7 \\
Pésimo & 2 & 2,2 & 0 & 0,0 \\
NS/NC & 2 & 2,2 & 1 & 1,1 \\
Total & 92 & 100,0 & 92 & 100,0 \\
\hline
\end{tabular}

Adican o tempo libre a: Facer deporte (72,8\%), Ver T.V. (68,5\%), Ver cine $(7,7 \%)$, Ler (22,8\%), Escoitar Música (33,2\%), Ir ó parque $(83,7 \%)$ e a Xogar con videoxogos $(47,8 \%)$.

O 25\% das nais e pais realizan algunha Actividade Física (tamén o 45,3\% doutros familiares), competindo o 1,1\% (o 11,4\% doutros familiares) e sendo Profesores de Educación Física tamén o 1,1\% (o $2,2 \%$ doutros familiares). Os restantes non a fan.Procedemento

Primeiramente, as familias tiveron que firmar un Consentimento Informado. Logo, procedeuse a aplicar o Cuestionario en cada clase tratando de solucionar as dúbidas que xurdiran. $\mathrm{O}$ proceso duraba en torno a 20 minutos de media para cada alumno. Finalmente, foi a recollida das Notas.

As Variables independentes analizadas foron Idade, Sexo, Peso, Altura, Notas Académicas e IMC. E as Variables dependentes: Práctica de Actividade Física e Deporte Extraescolar, Tipo de Actividad Física, Lugar de realización da Actividade Física ou Deporte Extraescolar, Tempo dedicado á Actividade Física ou Deporte Extraescolar, O Acto de Competición, Tipo de Competición e Tempo dedicado a la Competición.

Trátase dunha investigación cuantitativa, transversal, na que realizase unha estadística descriptiva (frecuencias e porcentaxes) e analítica (relación entre variables). Para o análise de datos,empregamos o SPSS/21.

O 72,83\% realizan algunha Actividade Física extraescolar: o Atletismo (73\%), Fútbol (70\%), Balonmán (50\%), Baloncesto (38\%), Natación (16\%), Ximnasia (7,4\%), Patinaxe (6,9\%), Tenis (4,5\%), Xadrez (3\%) e Artes Marciais (1\%). Atopamos que as Notas Académicas teñen relación significativa coa práctica de Balonmán ( $F=3,983 ; \mathrm{p}=0,018)$ e de Baloncesto $(F=5,768 ; p=0,009)$, e non có resto dos deportes e que o IMC ten relación significativa coa práctica de Fútbol $(F=4,568 ; p=0,034)$, Balonmán ( $F=$ 
3,743; $\mathrm{p}=0,046)$ e Tenis $(\mathrm{F}=6,456 ; \mathrm{p}=0,004)$, non así cos restantes.

Tendo en conta ás tres principais Actividades Físicas Extraescolares dos enquisados, atopamos que levan 1 (22,8\%), 2 (46,4\%), 3 (26,9\%) e máis de 3 $(2,1 \%)$ anos desenvolvendo dita actividade. O Tempo de Práctica da Primeira Actividade non se relaciona de xeito significativo coas Notas Académicas ( $\mathrm{F}=5,435$; $\mathrm{P}=0,345)$ e sí co IMC $(\mathrm{F}=1,345 ; \mathrm{p}=0,046)$.

No que se refiere ao lugar de realización da Primeira Actividade, observase que hai case os mesmos suxeitos dentro (47,6\%) e fora $(41,2 \%)$. E o Lugar de Realización da Primeira Actividade non se relaciona significativamente coas Notas Académicas $(\mathrm{F}=4,567 ; \mathrm{p}=0,657)$ nin co IMC $(\mathrm{F}=3,456 ; \mathrm{p}=0,345)$. A esta Primeira Actividades Física o 45,7\%, adicalle 2 días, o 36,3\%, 3 días, o 12,5\%, 8 días e o 3,5\% máis de 3 días, adicándolle 1 (40\%), 2 (44,3\%) ou 3 (10,7\%) horas/día. Os Días de Práctica non se relacionan de xeito significativo coas Notas Académicas ( $F=6,789$; $\mathrm{p}=0,346)$ e sí co IMC $(\mathrm{F}=7,630 ; \mathrm{p}=0,008)$ e as Horas de Práctica diarias da Primeira Actividade non se relacionan de xeito significativo coas Notas Académicas $(\mathrm{F}=6,780 ; \mathrm{p}=0,457)$ e sí co IMC $(\mathrm{F}=3,468$; $\mathrm{p}=0,018$ ).

O 59,8\% compite na sua Actividade Principal de xeito Local (23,5\%), Provincial (53,2\%), Autonómico (4,5\%) e Internacional (9\%, Semanalmente (48,7\%) Mensualmente (12,3\%), Semestralmente (4,7\%) e Anualmente (4,7\%). O feito de competir non está relacionado Notas Académicas $(\mathrm{F}=5,467 ; \mathrm{p}=0,439)$ nin co IMC $(\mathrm{F}=4,432 ; \mathrm{p}=0,347)$, o Tipo de Competición non se relaciona de xeito significativo nin coas Notas Académicas ( $\mathrm{F}=2,328$; $\mathrm{p}=0,324)$ nin co IMC $(\mathrm{F}=0.347 ; \mathrm{p}=0,887)$ e o Tempo de Competición non se relaciona significativamente coas Notas Académicas $(F=5,670 ; p=0,762)$ nin co IMC $(\mathrm{F}=0,329 ; \mathrm{p}=0,896)$

A metade realizan Actividades Extraescolares por pracer, mentres que un de cada 4 asegura que as fai porque lle obriga a familia. Con porcentaxes similares e preto do $50 \%$, o alumnado compite porque lle gusta ou porque os fan as amizades. En caso de ter exame e adestramento optan por non ir adestrar e estudar nunha porcentaxe preto do $50 \%$ e o $32 \%$ optan por adestrar e non estudar. O 67,16\% non se sente agobiado/a e os docentes/familia non ameaza ou castiga sen adestrar ante un mal comportamento (46\%). O 31,13\% considera que practicar deporte lles fai mellor persoa.

A familia o considera Moi bo (14,9\%), Bo (56,7\%), Regular (22,4\%), Malo (1,5\%) e Pésimo (0\%) deportista; mentras que eles mesmos consideranse Moi bo (23,9\%), Bo (40,3\%), Regular (35,8\%), Malo (0\%) e Pésimo (0\%) deportista. O 86,57\% gustaríalle adicarse ó deporte, como Profesional (34,33\%), para pasalo ben (26,87\%), practicar deporte no tempo libre $(19,40 \%)$, facer novas amizades $(16,42 \%)$ e para se
Adestrador (2,98\%). O 52\% consideran os estudos como o máis importante, a vida social (9\%) e o deporte (6\%), ainda que, fóra do hjorario escolar, adicanlle o tempo o deporte (48\%), os estudos (15\%) e a vida social (3\%).

Os motivos polos cales o alumnado non practicaba Actividades Físicas Extraescolares foi porque non lle gustaba $(46,2 \%)$, por a sua saúde (11,5\%), escasa valía $(23,1 \%)$, falta de tempo $(15,4 \%)$ e por preferir outros xogos (3,8\%) e o $61,54 \%$ non lles gustaría facer algún deporte e, ademáis o 7,69\% practicaban algunha actividade diferente do deporte.

\section{Conclusións}

Trátase dun estudio feito con 92 nenos/as de dous colexios públicos, onde algo máis da metade son mulleres, cunha media de idade de 11 anos Os enquisados roldan os $44 \mathrm{~kg}$ de media e os $140 \mathrm{~cm}$ e a media do IMC colócase en torno a 20 , polo que o alumnado se atopa en rango normal. A sua nota media está no 6,77 puntos.

No referente xa ó alumno é interesante destacar que case a metade de estudantes afirma que estuda porque lles gusta, porcentaxe máis pequeno (73,5\%) do obtido por Ponce de León (1998); mentres que un de cada tres faino por obriga. Unha ampla maioría dos enquisados leva os deberes ó día e o motivo de levar eses deberes ó día que se repite con maior frecuencia é o de "para non ter problemas no colexio". Resultan paradóxico estes datos en confrontación co da dificultade para facer os deberes. Dous de cada tres alumnos afirman ter dificultades, que para resolvelas recurren ao profesor particular e a s amizades.

Outros datos interesantes foron o de porcentaxe de alumnos que non facía tarefas escolares pola súa conta se non tiña deberes e a de alumnos que non facía tarefas escolares en vacacións.

A pesar das dificultades dos alumnos/as na escola un gran número de enquisados vese a sí mesmo como bo ou regular estudante e as súas familias tamén teñen unha opinión boa dos seus fillos como estudantes con porcentaxes similares. No tocante ó tempo libre moitos dos enquisados afirman facer deporte ou ir ó parque. Tamén é salientable destacar que a porcentaxe de alumnos/as que afirma ir ó cine e moi baixa. Pola súa parte, Ponce de León (1998), afirmaba que facían deporte o $57,8 \%$, mentres que o cine, ó igual que no presente estudo, obtiña porcentaxes moi baixos.

Deixando de lado ó alumnado e centrándose novamente no seu núcleo familiar apreciase que sete de cada dez pais e nais non practican actividade física aínda que os números son mellores cando se refire a outros familiares (seis de cada dez a practican).

A pesar de que os pais e nais non soen practicar exercicio físico, un gran porcentaxe de alumnado sí o realiza. Esta porcentaxe é similar a do estudo realizado por Escribano et al. (2012) no que o 
68,8\% practicaba exercicio físico. Nesas Actividades Físicas Extraescolares, o deporte máis practicado é o Atletismo, seguido do Fútbol, e do Balonmán.

En relación ós deportes débese indicar que existe relación significativa $(\mathrm{p}<.05)$ entre a práctica de Balonmán e de Baloncesto e as Notas Académicas non obtendo nos demais deportes relación significativa. Tamén a hai entre a Práctica de Fútbol, de Balonmán e de Tenis e o IMC. E dicir, quenes practican Balonmán ou Baloncesto obteñen mellores resultados académicos e quenes practican Fútbol, Balonmán e Tenis teñen uns Índices de Masa Corporal mellores que quenes non os practican.

No tocante ó Tempo de Práctica vese que para a Primeira Actividade a maior porcentaxe atópase nos “dous anos". O Tempo de Práctica relaciónase significativamente $(\mathrm{p}<.05)$ coas Notas Académicas.

En relación ó Lugar de Realización para a Primeira Actividade predomina a opción "dentro do centro” e con respecto ós Días de Práctica, para a primeira actividade a opción máis indicada é “dous días”. Nas Horas de Práctica, para a Primeira Actividade a opción predominante é "dúas horas (44,3\%).

No relativo á Competición, para a Primeira Actividade seis de cada dez afirman que compite. Para quenes compiten, preguntóuselle polo Tipo de Competición e a opción máis sinalada foi "provincial” con máis da metade das respostas. Para o Tempo de Competición, para a primeira Actividade case a metade indicou a opción "semanalmente”.

En relación ós motivos de realizar Actividades Físicas Extraescolares, a opción máis sinalada foi a de "Gústame" con máis da metade, mentres que dous de cada dez afirman que é porque os obrigan na casa. Do mesmo xeito os motivos de competir que indican os alumnos son porque lles gusta ou porque os obrigan.

Ante a coincidencia dun exame e dun adestramento case a metade optan por non adestrar e estudar, mentres que un de cada cinco opta por facer as dúas cousas.

Para a maioría dos enquisados, practicar deporte faite mellor persoa e catro de cada dez dos que realizan Actividades Físicas Extraescolares cre que é un bo deportista, porcentaxes similares $(45,6 \%)$ aos aportados por Ponce de León (1998).

Tamén é salientable sinalar que nunha vida adulta, a nove de cada dez lles gustaría ter relación co mundo do deporte como deportista profesional.

Por outra banda máis da metade do alumnado considera máis importante os estudos que o deporte ou a vida social. Sen embargo, cinco de cada sete dedican máis tempo o deporte fóra do horario escolar.

Dentro do alumnado que non practica Actividades Físicas Extraescolares, a razón máis importante é a de" porque non lles gusta” e nese mesmo grupo seis de cada dez afirman que non a practicaría ainda que puidera.

A tenor de todos os resultados e todas as conclusións débese finalizar este apartado dicindo que hai poucas variables que teñan relación significativa $(\mathrm{p}<, 05)$ tendo en conta os obxectivos propostos. Isto débese a que a mostra é pequena. Aínda así cabe destacar que se vislumbra unha certa influenza da práctica de Actividade Física no Rendemento Académico. En futuras investigacións, con mostras máis representativas, os resultados serán máis concluintes.

Tendo en conta os resultados acadados, faise preciso realizar algún tipo de intervención educativa que permita millorarlos, no sentido de incrementar a práctica de la Actividad Física, dende as primeiras etapas evolutivas, tales como as que seguen:

O primeiro, reunirse cos pais e nais antes de comezar o curso académico para informalos sobre os resultados do presente estudo. Incidirase na influenza que ten a Actividade Física no Rendemento Académico e no IMC dos seus fillos/as. Tamén se lles comentaría os resultados nos cales eles son partícipes como a Actividade Física da familia xa que aínda que non garde relación coa práctica de exercicio físico por parte do fillo/a si pode ser un factor a ter en conta. Nesa reunión tamén se lles explicaría os beneficios que ten o exercicio físico e consecuentemente as actividades estraescolares. Nestas reunións tamén se lles falaría da importancia da Alimentación para contribuir a ter un IMC máis acorde os rangos determinados para cada idade. A esa reunión ou reunións grupais podería sumarse algunha reunión puntual con algún pai ou nai. A segunda medida a considerar consistiría en establecer unhas semanas de fomento do Deporte na que todo o claustro de profesores/as sería partícipe. Estas semanas serían ó principiar cada trimestre e os alumnos practicarían diversos deportes relacionados cos seus gustos con competicións por equipos, individuais, xogos e deportes de cooperación, xogos de elliminación, etc. Con relación a isto, farianse premios para fomentar o gusto pola actividade física para aqueles/as alumnos/as que non practican Actividades Físicas Extraescolares.

Todos debemos contribuir a integrar ó alumno/a na actividade física nas vidas cotiás; por tanto a través destas actividades e dentro do ámbito educativo contribuiriase a esta labor. En relación con esta medida, débese indicar que ó finalizar o curso teriase unha día dedicado á Actividade Física na que xunto con colexios da zona fariase unha Maratón onde se practicarían deporte de equipo como o Balonmán, o Fútbol e o Baloncesto e individuais como o Tenis ou o Atletismo.

En terceiro lugar, fomentaríase a participación en carreiras populares como a carreira de San Martiño, en Ourense, ou a carreira do Lázaro, en Verín. 
Un grupo de alumnos/as do colexio acudirían a estas competicións en representación do centro. As andainas organizadas polo concello ou por diversas asociacións tamén formarían parte desta medida na que o obxectivo é achegar o alumnado ó deporte e ás Actividades Físicas Extraescolares para fomentar hábitos saudables. Ademais do anterior colaborariamos coas asociacións deportivas próximas ó colexio a través de saídas a recintos deportivos. Neste sentido, cabe destacar que na hora de Educación Física e durante o mes de xaneiro, os alumnos/as acudirían á piscina municipal para aprender a nadar ou mellorar a técnica. Outras visitas poderían ser meramente irnformativas como por exemplo asisitir ás instalacións do Verin CF ou de equipos da capital como o Ponte Ourense CF ou o UD Barbadás no que respecta ó Fútbol, o $\mathrm{COB}$, o $\mathrm{ABO}$ Verín, en Baloncesto, ou o Barrocás, de Hockey. Estas visitas cobran maior importancia se nos referimos ós resultados do noso estudo xa que estes deportes obtiveron relación significativa coas Notas Académicas e co IMC respectivamente. O obxectivo sería que moitos dos alumnos/as que fosen á visita se interesaran por inscribirse nas categorías inferiores do equipo.
Ademais sería conveniente que practicasen estes deportes unha vez á semana xa que segundo o resultados do noso estudo esta é a mellor opción para obter un incremento do Rendemento Académico.

Nestas saídas, os alumnos/as serían informados polo persoal encargado de cada entidade sobre aspectos organizativos e de funcionamento dos equipos co obxectivo de atraer ó alumnado para realizar Actividades Físicas Extraescolares nestes equipos. De igual maneira, cabería a posibilidade de que profesionais do deporte acudiran ós colexios para facerlles ver ós/as nenos/as a importancia de practicar exercicio físico. A participación voluntaria nestas actividades suporía un incremento de dous puntos na materia de Educación Física.

\section{Referencias}

Escribano, V.; González I.; González S.; Ladrón, C. \& López J. (2012). Influencia de la actividad física en el rendimiento académico dentro de la etapa de educación primaria. Universidad de Castilla - La Mancha.

Ponce de León, A. (1998). Tiempo libre y rendimiento académico. Logroño: Universidad de La Rioja 